\title{
Critical Examination of Information: A Discursive Approach and its Implementations
}

\author{
Fahri Yetim \\ Information Systems, University of Siegen, Germany
}

Fahri.Yetim@uni-siegen.de

\begin{abstract}
This paper presents a discursive approach to the critical examination of information and describes its implementation options. The approach provides a set of concepts to ensure that examination dialogs on information objects take place in a systematic way. For this purpose, this paper takes a critical perspective on information, considers structural characteristics of examination dialog, and arranges some basic categories of critical issues and discursive concepts from Habermas' (1984) discourse theory. In addition, this paper discusses the pros and cons of two implementation options of the theoretical concepts; this concerns their modeling as templates within the existing discourse-support system, Compendium, to provide users predefined-structures for examination dialogs and their implementation as features of a novel prototype, DISCOURSIUM, to facilitate critical discussions. Finally, this paper discusses extensions of the approach and illustrates, by means of a case example from argumentation theory, how the proposed concepts can be instantiated to provide participants of examination dialogs with context-specific questions for criticizing arguments. This research may be of value to practitioners as it provides them with categories of critical issues and with some orienting information on how the categories can be used to design further context-sensitive sets of questions.
\end{abstract}

Keywords: Examination of Information, Information Quality, Examination Dialogs, Argumentation, Discourse-Support Systems, Discourse Theory, Critical Research.

\section{Introduction}

Informing science is concerned with the provision of information in a form, format, and schedule that maximizes its effectiveness (Cohen, 1999). The "real world" informing systems involve many complexities as neither senders and receivers nor the communications pathways are homogeneous (Gill \& Bhattacherjee, 2007; Te'eni, 2001). Heterogeneities can be observed at different levels of communication (Yetim, 2004, 2007), such as the physical or media level (e.g., differences in technological standards), the syntactical level (e.g., differences in formats, language structures), the semantic level (e.g., differences in meanings of terms or ontology), and the prag-

Material published as part of this publication, either on-line or in print, is copyrighted by the Informing Science Institute. Permission to make digital or paper copy of part or all of these works for personal or classroom use is granted without fee provided that the copies are not made or distributed for profit or commercial advantage AND that copies 1) bear this notice in full and 2) give the full citation on the first page. It is permissible to abstract these works so long as credit is given. To copy in all other cases or to republish or to post on a server or to redistribute to lists requires specific permission and payment of a fee. Contact Publisher@InformingScience.org to request redistribution permission. matic level (e.g., differences in expectations, norms, values, and information needs of actors). These differences may not only affect the organization and transmission of messages, but may also have an impact on the receiver's perception and interpretation of the messages (Te'eni, 2001). Moreover, in the case of groups, differences in perceptions and interpretations may trigger discussions and negotiations among the group mem- 
bers: for example, among information receivers (or seekers) when they evaluate received information for acting in a context, or among information senders (or providers) when they communicate information to others for supporting their actions. Consequently, different aspects of information may become an issue of negotiation.

Consider, for example, the issue of relevance (Greisdorf, 2000; Schutz, 1970). Teams often need to make a collective decision on what information or knowledge is needed and, thus, should be created, managed, and transferred (Karamüftüoglu, 1998). Different expectations, interests, and values may lead to conflicts, which need to be articulated, negotiated and resolved. Another issue is the validity of information, whose evaluation may become controversial due to differences in conditions of the creation and transmission of the information. The assessment of the validity of information can concern the authenticity of the person or the institution with which one is communicating as well as the authenticity of the information itself. The quality features of information have an impact on the trustworthiness of information and also involve ethical-moral issues (Capurro, 2000; Gackowski, 2006; Knight \& Burn, 2005; Kuhlen, 1999). Finally, rationality issues may arise as people do or prefer to do things in different ways (Habermas, 1984). They concern the rationality of activities or processes related to the creation of information as well as to the interaction with information (e.g., the rationality of search activities or navigation options offered by online books or user interfaces).

This paper takes these kinds of challenges with the information at its disposal. It starts from the premise that, while constructing information for others and/or interpreting information from others, diversities at multiple levels entail complexities and uncertainties as well as conflicts. This paper suggests a discursive approach to deal with the forms, contents, and norms of information in a reflective way. Inspired mainly from Habermas' (1984) discourse theory, previous research has already theoretically argued for taking a critical or discursive perspective on information (e.g., Stahl, 2006; Ulrich, 2001; Yetim, 2006). In addition, some works have demonstrated the practical relevance and usefulness of discourse-oriented approaches and tools for supporting sense-making activities, i.e., capturing, comprehending and managing competing interpretations and arguments (e.g., Buckingham Shum, 2006; Klamma, Spaniol, \& Jarke, 2005; Uren, Buckingham Shum, Bachler, \& Li, 2006). Finally, it has also been empirically confirmed that adding structures to online discussion environments improves a group's ability to reach consensus and make higher-quality decisions (Farnham, Chesley, McGhee, Kawal, \& Landau, 2000), and that a structured dialogue approach is the more thoughtful approach to learning and reasoning when compared with a less structured dialogue approach addressing the same task (Ravenscroft \& McAlister, 2006).

The current discursive approach aims to facilitate structured and critical examination dialogs on information objects (texts, information design, etc.) and thereby to promote cognitive inputs and expertise from diverse perspectives. For this purpose, it integrates a set of core issues associated with information and with discursive concepts from Habermas' (1984) theory to provide the basis that reflective communications on these issues take place in a systematic way. The issues range from how to communicate comprehensible, relevant, and valid information to how to accommodate diverse ethical values. In addition, this paper describes two implementation options of the proposed theoretical concepts and reflects on their merits and limitations. The first implementation concerns their modeling as templates for examination issues within the 'Compendium' discourse-mapping system, and the second, their realization as system features of a novel prototype, DISCOURSIUM. Finally, this paper justifies and illustrates, with the help of a case example from argumentation literature, why and how these concepts can be used to provide participants with context-specific critical questions for criticizing arguments. All in all, this research may be of value to practitioners as it provides them with categories of critical issues and with some orient- 
ing information on how the categories can be used to design further context-sensitive sets of questions.

This paper is organized as follows. The first section introduces the approach and its conceptual foundations. The second section illustrates the realization of the theoretical concepts within the context of Compendium and DISCOURSIUM and also reflects on the trade-offs. The third section discusses the usage of the concepts for constructing different sets of concrete questions for criticizing arguments. The final section provides some discussions and conclusions.

\section{The Approach and its Conceptual Foundations}

This section presents the approach with its conceptual basis in the following way. First, it briefly discusses the concept of information with its related concepts to provide a clear understanding of how this concept is used in this work. Then it seeks to understand the structural characteristics of examination dialog as they are described in the current literature. Based on these understandings, the paper justifies why and how the concepts and architectures of the meta-communication model proposed earlier by Yetim (2006) can be used to structure dialogs for examining information. Finally, this section describes how the model arranges some basic issues and the discourses from Habermas' (1984) theory to provide guidance for what aspects of information should be examined and how the examination should be done.

\section{On the Concept of Information}

There are different views on the concept of information and its relation to other concepts, such as data or knowledge. The diversity of views concerns not only the definition of these concepts, but also the direction of transformation from one into another (e.g., Alavi \& Leidner, 2001).

One commonly held view is that data consists of raw numbers and facts, information is processed data, and knowledge is authenticated information (Dretske, 1981; Machlup, 1980). Knowledge is regarded as information stored in the minds of individuals; it presumes a hierarchy from data to information and from information to knowledge. Against this view, it has been argued that the assumed hierarchy from data to knowledge is actually inverse; knowledge must exist before information can be formulated and before data can be measured to form information (Tuomi, 1999). In other words, knowledge exists and becomes information when articulated, verbalized, and structured, and information becomes data when assigned a fixed representation and standard interpretation (Alavi \& Leidner, 2001). Despite the differences in their understanding of the hierarchy, both views share the assumption that knowledge does not exist outside the knower. Either information is converted into knowledge once it is processed in the minds of individuals, or knowledge becomes information once it is articulated and presented in the form of text, graphics, words, or other symbolic forms (e.g., Drucker, 1994).

On the other hand, what some researchers call information is for others explicit knowledge (Nonaka \& Takeuchi, 1995), codified knowledge (Zack, 1999), objectified knowledge (Spender, 1996), or public knowledge (Boisot, 1995). Berger and Luckmann (1966) speak of a social stock of knowledge, which is constructed through the articulation of subjective experiences, i.e., a person's subjective knowledge is translated into signs and transmitted to other persons. Kuhlen (1999) defines information as a subset of knowledge that is relevant for a specific action. "Information work" takes existing knowledge and transforms it in such a way (i.e., adds value to it) that it can more easily become information (i.e., understandable and relevant) for specific actions.

With respect to their action relationship, knowledge and/or information are regarded as necessary conditions for rational action. People not only have knowledge about things, but also knowledge for action, and knowledge can also be gained in and through action (Schön, 1983). Habermas (1984) points out that possession of knowledge alone cannot secure rational practice and that "ra- 
tionality has less to do with the possession of knowledge than with how speaking and acting subjects acquire and use knowledge" (p. 8).

Inspired by Habermas' works, Ulrich (2001) discussed the relationship of three concepts, "information," "knowledge," and "rational action," and organized them in the form of a 'staircase' within the context of Information Systems Development (ISD). He defines ISD as "systems definition, design, and development with a view to providing people with information for purposeful action" (p. 57) and thus argues for reflecting on these core concepts within the ISD. In the context of the Web, Yetim (2007) extended the one-sided staircase for reflection and suggested an interpretation of the relationship of these concepts from two different perspectives, the perspective of the receiver and that of sender, as shown in Figure 1. Accordingly, the left side of the double-sided staircase expresses the perspective of receivers/users of information whereas the right side the perspective of senders/providers of in-

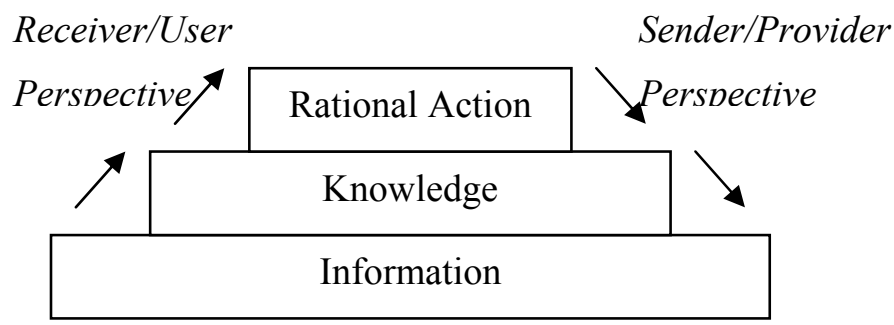

Figure 1: Information, knowledge, and rational action. formation.

From the perspective of a receiver, data becomes information when it is comprehensible and relevant. Being comprehensible and relevant does not also mean being valid or free of errors. Information becomes knowledge when it is validated. Knowledge is then applied for conducting rational action (i.e., information $\rightarrow$ knowledge $\rightarrow$ rational action). In other words, in the receiver's perspective, an actor's main goal is conducting rational action and reflecting whether received information is also relevant knowledge for that purpose (e.g., is this information reliable? Does it allow rational practice?).

In the provider's perspective, an actor's main goal is informing others (i.e., rational action $\rightarrow$ knowledge $\rightarrow$ information). Actors(s) can reflect on what knowledge (or subset of knowledge) and experiences from previous actions should be provided/articulated/transferred and in what form in order to become information for the potential receivers (e.g., What knowledge was useful? What knowledge was not appropriate? How should I articulate and transfer my experiences? For whom? For what purpose?).

Both perspectives can be taken by a single person. For example, a lecturer searching for slides on the Web can critically examine the slides found before using them in the class (receiver perspective) and rewrite/improve them (i.e., constructing information for others) after having used them (sender perspective). However, as mentioned in the introduction, this paper focuses on cases where receivers or senders are groups of actors. Therefore, the remainder of this section is concerned with structures of examination dialog to support such groups during the interpretation and use of information received from others as well as during the articulation and transferring of experiences as information to others.

\section{Structural Characteristics of Examination Dialogs}

In an earlier work, Walton and Krabbe (1995) distinguished six primary types of human dialogs: (1) Information-seeking dialogs (where one participant seeks the answer to some question(s) from another participant); (2) Inquiry dialogs (where participants collaborate to answer some questions); (3) Persuasion dialogs (in which one participant seeks to persuade another to accept a statement); (4) Negotiation dialogs (where the participants bargain over the division of some scarce resource); (5) Deliberation dialogs (where participants collaborate to decide what action(s) 
should be adopted in some situation); (6) Eristic dialogs (in which participants seek to vent perceived grievances).

Recently, this classification has been extended with a special type called examination dialog (Dunne, Doutre, \& Bench-Capon, 2005; Walton, 2006). According to Dunne et al. (2005): "In such dialogues one party - the Questioner Q - elicits statements and opinions from another - the Responder R - with the aim of discovering R's position on some topic, either to gain insight into R's understanding and knowledge of the topic, or to expose an inconsistency in R's position" (p. 1560). They also state that examination dialogs may "be nested within information seeking dialogues: probing for inconsistency increases confidence in the veracity of R's beliefs; similarly, in persuasion dialogues, exposing inconsistency is a useful prelude to persuasion" (p. 1560).

Walton (2006) presents a similar view and argues that examination intervals can occur in various kinds of dialogs and that examination dialog is more than just information seeking as it also involves elements of persuasion dialog. Concerning the central characteristics of examination dia$\log$, Walton states that this type of dialog has two goals: (1) the extraction of information and (2) the testing of the reliability of this information. The first goal is achieved by two means: by asking questions in order to obtain information from the respondent and by an exegetical function used to obtain a clear account of what the respondent means to say. The second goal is achieved through critical argumentation used to judge whether the information elicited is reliable. The information is tested, for example, against other known facts or statements.

In relation to these goals, Walton (2006) distinguishes two basic levels of examination dialog and states that examination as a whole needs to be seen as based on a characteristic dialectical shift from the first level to the second. In the case of examination of written texts, for example, an examination dialog begins with some text of discourse in natural language. At the first level, the exegetical reconstruction of a text needs to be judged on its own merits. In this clarification mode, meaning may be negotiated between the participants. The second level is more openly argumentative. The dialog at this level can have the form of critical discussion, in which the critic may, for example, express doubt about the argument attributed to the author. Somebody may represent the viewpoint of the author and may respond to the critic. Thus, Walton concludes, "It is the joining together of these two levels that represents the structure of examination and defines it as a type of dialogue" (p.775).

\section{Using Meta-Communication Model for Examining Information}

Both the characteristics of examination dialog and our understanding of information concept suffice to articulate our point of view. First, Walton's characterization of examination dialog has similarity with the two-level architecture of meta-communication (Hoppenbrouwers \& Weigand, 2000; Yetim, 2006), which distinguishes between the conversation for clarification level, where clarifications take place, and the discourse level, where conflicts are discussed with arguments. For example, when we regard a text of natural language (e.g., a Wikipedia article) as an object of the communication level, an examination dialog on the text can be viewed as a type of meta-level communication. During meta-communication, participants may first enter the conversation level to resolve some problems and shift from clarification mode to discourse mode to resolve conflicts. Hence, the conclusion we draw from this similarity is the applicability of the two-level meta-communication architecture for structuring examination dialogs.

Second, the meta-communication model (Yetim, 2006) integrates several key issues and discursive concepts at each of the two levels, concepts which are partly driven from the information and its related core concepts and partly from Habermas' (1984) discourse theory. Hence, we claim that the meta-communication model synthesizes a set of structures and concepts needed for examining information in a critical and systematic way. Before describing them in detail we elaborate a 
little more on the rationale of the two levels of the meta-communication architecture and their use in this paper.

Walton (2007) states that clarifications are needed in different situations: for example, when difficulties arise due to ambiguity or incomprehensibility in dialog or texts. The purpose of clarification in dialog is to help to understand an obscure or otherwise problematic utterance of the other party. Clarifications may involve explanations and also arguments to help to resolve problems. However, there are also many situations where problems cannot be solved by clarifications alone and need further argumentations to resolve different positions. Let us consider such an example to explain the rationale for the two-level architecture. The case example is taken from (Walton, 2006, cited in Walton, 2007, p. 5) and deals with the issue whether a man's accidental death was covered by his insurance policy according to the contract.

The plaintiff's husband died as a result of a motor vehicle accident which occurred in Barbados. The bus in which the man died was transporting him, the plaintiff, and others from their hotel in Barbados to the airport at the end of their 14-day vacation. The couple had purchased the vacation package through an agent. As part of the package they purchased accident insurance under a group policy. The policy provided $\$ 45,000$ in coverage for death occurring in consequence of riding in: (1) any aircraft . . ; or (2) 'any airport limousine or bus or surface vehicle substituted by the airline'. The policy provided $\$ 15,000$ in coverage for death arising out of the use of other public conveyances. The plaintiff argued that the words 'substituted by the airline' in (2) above referred only to the words 'surface vehicle'.

In this example, the problem arose because of the ambiguity of clause (2), due to its obscure sentence structure, which led to two different interpretations of the meaning of this clause:

(A) 'any airport limousine, or bus or service vehicle substituted for an aircraft by the airline'.

(B) 'any airport limousine or bus, or service vehicle substituted for an aircraft by the airline'.

The insurance company argued that (A) should be taken to be the intended meaning of clause (2). On this interpretation, the bus was the normal mode of transport from the hotel to the terminal, so the insurance company did not have to pay the $\$ 45,000$ death benefit. In contrast, the plaintiff argued that clause (2) should be interpreted as meaning (B). On this interpretation, the bus did not have to be "substituted" for an aircraft, so the insurance company would have to pay out the $\$ 45,000$ death benefit. Walton (2007) argues that the problem in this case cannot just be solved through clarifications, i.e., by asking the framers of the contract what they meant to say. Instead, a third party or the judge has to examine the arguments and evidences on both sides and decide which interpretation is the more reasonable, given the facts and legal rules relevant to the case. Walton also points out that what the judge does may partly be seen as a clarification dialog, but also as a kind of meta-dialogue about a first level dialogue in which a dispute between two sides takes place.

In this paper, the clarification dialog (e.g., about the contract) corresponds to the first level of the meta-communication model whereas the argumentative disputes between parties correspond to the second, i.e., the discourse level. Yet, there are some differences concerning the use situations of the model. Firstly, the clarification level is not only entered as a reaction to problems or breakdowns that occur in a dialog, e.g., when interpreting information received from others. The clarification dialog can also be entered while designing information (e.g., the contract) for future use situations. In (Yetim, 2006) the meta-level reflections in different use situations (i.e., before, during, and after the execution of an action) are characterized as ex ante meta-communication, metacommunication-in-action, and ex post meta-communication.

Secondly, the current paper does not limit examination dialog to a conceptualization based on a dyadic dialog (Questioner and Responder). Instead it considers broader, group-based collaborations for critical examination. This means both clarifications and the argumentations can take 
place among a group of receivers or senders. The two-level architecture can reduce complexity in group communication as it separates just talking from argumentative conflict resolution. In many cases, the clarification level can involve explanations and also justifications of positions and may lead to the resolution of the problem so that there is no need for further discussion. The argumentation at the discourse level requires the existence of a conflicting position that participants can argue for or against with reasons. Making the conflicting positions at the discourse level visible may relieve actors from the burden of having to read all the conversations at the clarification level.

As mentioned above, the meta-communication model additionally integrates several concepts for both the clarification and the discourse level to enable structured examination of information. We have already claimed that they are relevant for the interpretation and use of information received from others as well as for the articulation and transferring of experiences as information to others. Next, we describe them in detail.

\section{Concepts for Structuring the Clarification and Discourse Level}

Figure 2 summarizes the basic issues and related discourses that structure the two levels of the model. The clarification issues are derived from an analysis of the core concepts of information, knowledge, and standards of rationality of actions. In clarification dialogs, they provide orientation by making us aware of what aspects need to be paid explicit attention. The discourse level is structured by a set of discourses proposed by Habermas $(1984,1996)$. They provide orientation by making explicit where which type of conflicts can be resolved with arguments. In Yetim (2006), the issues and discourses are interrelated so that for each issue there is a related discourse. In Figure 2 we ignore this interrelationship as we will explore different options for their implementation in the next section.

At the clarification level, to clarify information aspects, the following semiotic issues (extended from Ulrich's (2001) work) are considered: Physical, Syntactic, or Semantic Clarity of signs and Relevance of signs. This is consistent with the view that information is something that is understandable and relevant or that data become information when they acquire context-dependent meaning and relevance.

The clarification of the validity of information (knowledge aspects) requires the move from semiotic to epistemological considerations. Knowledge is regarded as fundamentally discursive in the sense that claims to knowledge must always remain open to argumentative challenge (U1rich, 2001). Following Habermas (1984), the validity of signs (or utterances) can be assessed with respect to sincerity (Expressive Validity), truth (Empirical Va-

\begin{tabular}{|c|c|}
\hline Discourse Level & \\
\hline \multicolumn{2}{|c|}{$\begin{array}{l}\text { Explicative Discourse, Pragmatic Discourse, Therapeutic } \\
\text { Critique, Legal Discourse, Theoretical Discourse, Aesthetic } \\
\text { Critique, Ethical Discourse, Moral Discourse. }\end{array}$} \\
\hline Clarification Level & \\
\hline \multirow{2}{*}{\multicolumn{2}{|c|}{$\begin{array}{l}\text { Rationality Aspects: Instrumental Rationality, Strategic } \\
\text { Rationality, Aesthetic Rationality, Communicative Rationality; } \\
\text { Knowledge Aspects: Expressive Validity, Empirical Validity, } \\
\text { Normative Validity; }\end{array}$}} \\
\hline & \\
\hline $\begin{array}{l}\text { Information Aspect } \\
\text { Semantic Clarity, } R\end{array}$ & $\begin{array}{l}\text { hysical Clarity, Syntactic Clarity, } \\
\text { ance. }\end{array}$ \\
\hline
\end{tabular}

Figure 2: Concepts for structuring examination dialogs. lidity), and appropriateness (Normative Validity). That is, information should be not only comprehensible and relevant, it should refer to the true (commonly believed) state of affairs, reflect sincere pragmatic intentions, and be communicated in accordance with accepted social norms. 
Clarification of the rationality aspects is based on the assumption that clear information and valid knowledge alone cannot secure rational practice. It requires both justified knowledge and its successful transformation into effective and efficient action and justified normative implications for those involved and affected. It is thus related to the ethical core of action and is concerned with the interpersonal "rightness" (appropriateness, desirability, legitimacy) of action (Ulrich, 2001). These aspects are covered by Habermas' (1984) three rationality concepts, i.e., Instrumental, Strategic, and Communicative Rationality. We additionally consider the Aesthetic Rationality of signs. Concerning this addition we should note that we understand aesthetic action as oriented towards perception and experience, and aesthetic rationality can be characterized by an interest in the presentation of experience qualities (Seel, 1985). Recent research has demonstrated the importance of creating aesthetically pleasing design (Norman, 2004; Tractinsky, Katz, \& Ikar, 2000). Actors designing information can clarify whether signs presented are in accord with or deviate from culturally established standards of aesthetic values.

Concerning the discourse level of the model, the basic idea is that claims to information (comprehensibility and relevance of signs) and knowledge (validity of information) as well as to the rationality of the use of knowledge are open to discursive challenge. To deal with these issues in a discursive way, participants of examination dialog enter discourses to resolve conflicting views with arguments. Habermas $(1984,1996)$ suggests different discourses for different issues. They are: Explicative Discourse for justifying the comprehensibility of signs; Pragmatic Discourse for justifying the relevance (purposefulness) of the choices; Therapeutic Critique for critical examination of the sincerity of expressions; Legal Discourse for justifying the legitimacy of actions/expressions; Theoretical Discourse for explaining/justifying the truth of expressions and the efficacy of actions; Aesthetic Critique for critical examination of aesthetic value standards; Ethical Discourse for justifying actions from a (cultural) value perspective; Moral Discourse for justifying the universal rightness of norms or practices.

At this point we should note that Habermas (1984) does not use the term 'discourse' for reflection on the truthfulness of expressions and evaluative judgments, as universal agreement serves as an ideal for none of them. If the sincerity of a speaker's claim is challenged, the speaker cannot show her sincerity by arguing, rather by acting in a manner consistent with her expressed intentions. Yet, arguments can still play a role in persuading others. Similarly, people can adopt a reflective attitude to the value standards even though the cultural standards of value at issue do not include a claim to universality. In aesthetic criticism, arguments serve to "guide perception and to make the authenticity of a work so evident that this aesthetic experience can itself become a rational motive for accepting the corresponding standards of value"(Habermas, 1984, p.20). In the remainder of this paper, we ignore these differences between discourses and other reflective media and consider all the concepts at the discourse level as spaces to provide arguments for conflicting positions with respect to the related issue(s).

Finally, after having introduced the taxonomies of critical issues and related discourses, final arguments for this differentiation and making them explicit should be noted. First, the practical side is thoroughness of critical awareness. This paper argues that these distinctions, utterly ignored or mind-boggling to the vast majority of users, force clearer thinking about the different dimensions of argumentative discourse. Ultimately the classifications adopted from Habermas and linguistic theory could serve as an inventional resource, compelling a broader examination of the evidence underlying a claim and generating resources for formulating responses (hence the urgent need to categorize opposing as well as supporting arguments). Second, a more abstract and social rationale could underpin this project. Habermas embarks on his theory of communicative action for what he considers a vital social reason. Unless we can systematically unravel the ways that arguments work, we are left with fundamentally irrational means - such as brute force or coercion- 
for persuasion. Indeed, the very concept of dialogue offers an alternative to domination via ideology, at least for Habermas.

\section{From Theory to Practice}

This section describes how the theoretical concepts presented so far have been implemented to support collaborative examination dialogs. For this purpose, two issues are the focus of interest. First, how can they be integrated in an existing discourse-support system such as Compendium? Second, how can they be designed as features of a novel prototype to overcome the limitations of the first option? As the developed artifacts have not yet been evaluated in use contexts, our reflections on the implementation options have the nature of "reflection-on-action" (Schön, 1983), i.e., reflections of the designer on the resulting artifacts. This section also illustrates how theory informed the technical design and how practical challenges affected the realization of the theory.

\section{Integration of the Concepts in the Compendium Methodology}

Compendium (www.CompendiumInstitute.org) is both a tool and a methodology for facilitating discourses by enabling the capture and structuring of issues, ideas, arguments, and decisions. Compendium's ontology expresses Rittel's Issue-Based Information Systems (Kunz \& Rittel, 1970) and allows modeling dialogs around problems (Buckingham Shum, 2006; Conklin, 2005). Users can define their own ontology and map issues, ideas, or arguments in an unconstrained manner. The system can be used as a personal tool, or asynchronously in group, or in real time collaborative modeling. When using Compendium for group dialogs, facilitators of dialogs can create and save Issue nodes as reusable issue-template structures to seed different kinds of discussions. This capability of Compendium to provide predefined structure to aid structured conversations is one of its characteristics that particularly justifies our use of it to model the concepts.

As Compendium offers some flexibility concerning the usage of its links and nodes, there are different options for modeling the concepts as reusable templates for facilitating structured dialogs. For example, clarification issues and discourses may be represented either by Issue nodes or by maps. In addition, the two levels of examination dialogs may be realized as two separate levels or may be interconnected. Yet, independently of the modeling option chosen, the participants of examination dialog are expected to provide their contributions to the clarification issues and discourses. Depending on the implementation platform (e.g., face-to-face or online environment), the interaction of participants with the templates can be mediated by a facilitator in a synchronous or asynchronous way.

In what follows, we briefly summarize the modeling options and reflect on their pros and cons (Yetim, 2007).

(1) First of all, the simplest way to model the concepts of the two levels is to consider them as two separate patterns or templates for discussions, as shown in Figure 3(a). The issues at the conversation for clarification level are modeled by issue nodes whereas discourses are modeled by maps. Alternatively, one might model the clarification issues as maps to reduce complexity in discussions. The advantage of this modeling is the reduction of the concepts of two levels, as the issues and discourses are thematically related, and to allow the usage of only one of the two patterns to structure conversations. In both templates, the "communicative rationality" node is used to capture the decisions after discussing the issues. Although each pattern can seed conversations of different sorts with issues, positions, and arguments, the disadvantage of such modeling is that it does not separate conversations for clarifications from argumentation in support of a conflicting position, which has been the rationale behind the two-level architecture. 
(a)

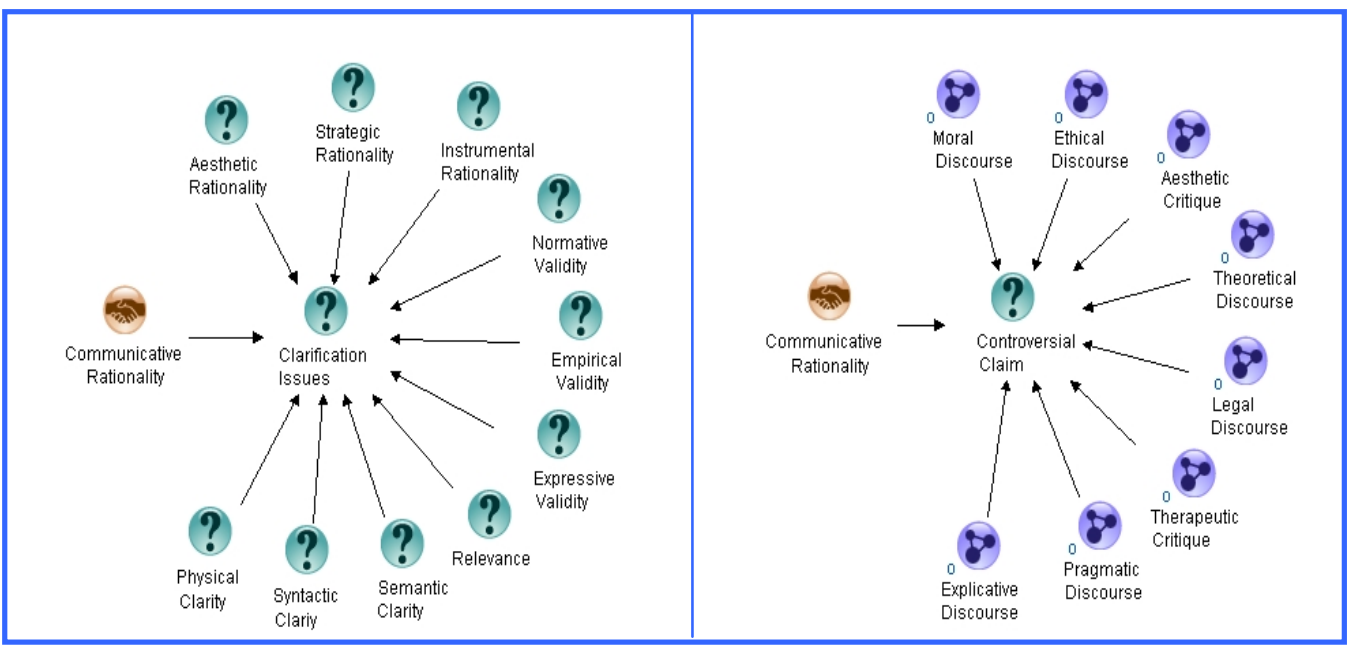

(b)

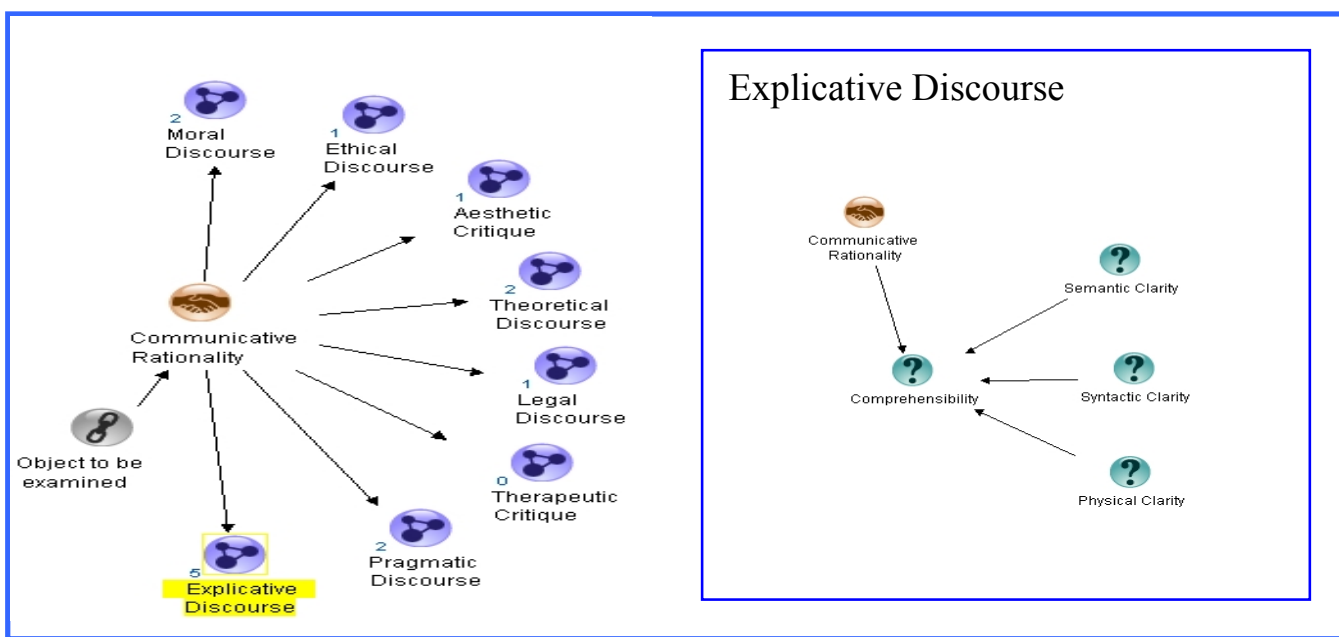

(c)

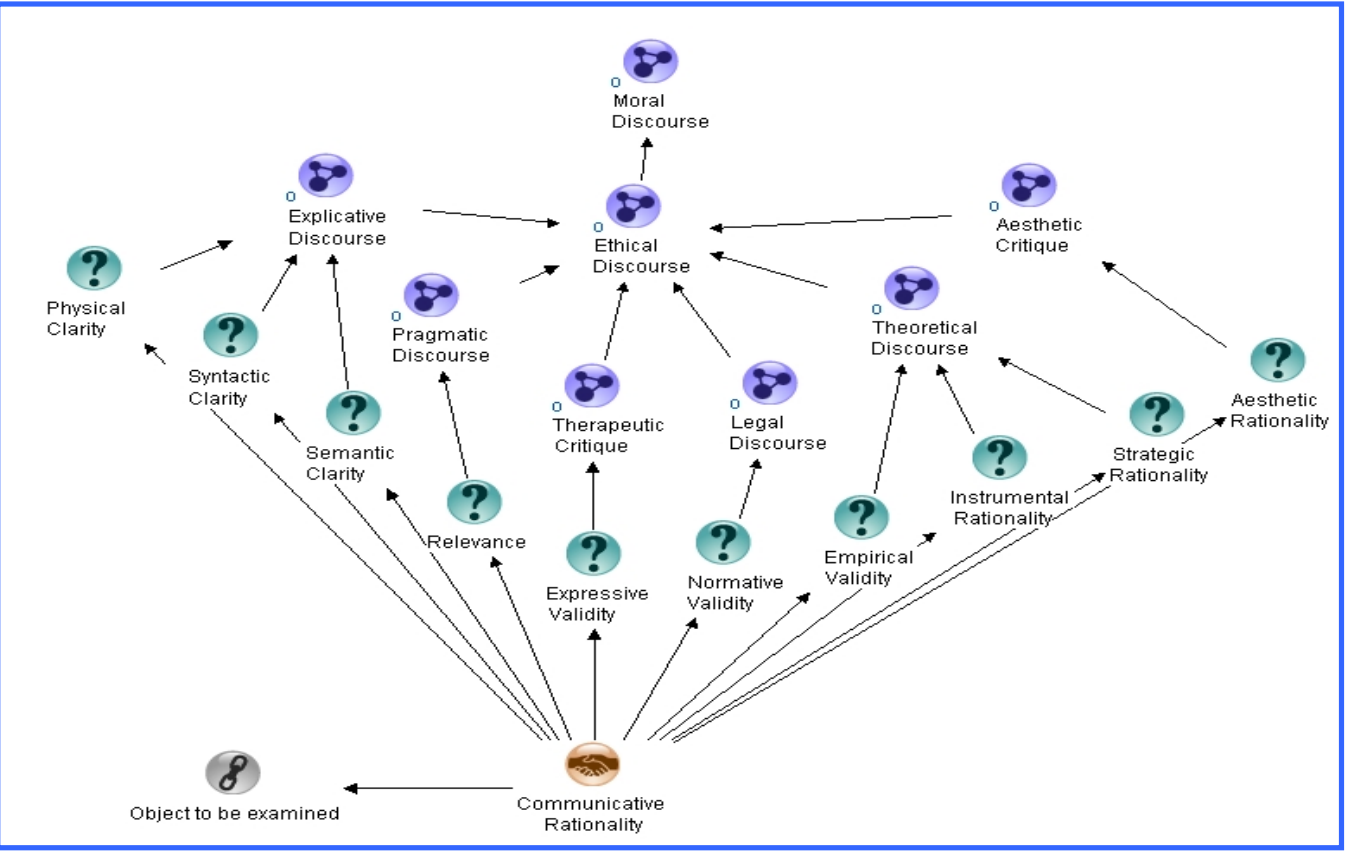

Figure 3: Modeling options with Compendium. 
(2) One way to realize the interconnection of concepts of both levels is integrating the issues into the related discourses. This option models each discourse as a map and integrates the clarification issues as Issue nodes within the related discourse maps, as shown in Figure 3(b). In this example, the issues dealing with the clarity of signs are integrated in the explicative discourse as the primary concern of the explicative discourse is examination of the controversial claim to comprehensibility of signs (Habermas, 1984). This option thematically structures or groups the conversations by discourse maps and, within each map, by specific issues. Hence, the advantage of such hierarchical organization is that it reduces the number of nodes visible to the users. On the other hand, it makes it difficult to clearly separate conversations around a clarification issue from arguments for conflicting positions related to the issue since it forces moderators to capture all contributions within the corresponding map.

(3) In contrast, Figure 3(c) shows a modeling option which best reflects the rationale behind the two-level architecture and clearly separates conversations for clarifications from argumentative discourses. The complex pattern for team deliberation provides participants with the clarification issues to which responses during examination dialogs can be linked, whereas emerging conflicting positions on each issue (including pro and con arguments) have to be captured within the related discourse map. In Compendium, the nodes can also be changed to maps to manage the complexity to some extent when contributions to issue nodes grow.

The advantage of this pattern is that it separates "just talking" and argumentation as advocated in the theoretical model (Yetim, 2006). Yet, some practical challenges for dialog mapping remain that concern the complexity it creates in real time dialogs. For example, when a conflict concerning the relevance of information arises, the controversial positions/arguments have to be placed into the pragmatic discourse map. These positions themselves can be criticized from different perspective, for example, from an ethical perspective. One way to do this is to link the new ethical position/argument to the related node within the same map (i.e., within the pragmatic discourse). When the acceptability of the ethical argument itself becomes controversial, its negotiation can be done either in the same map (i.e., in the pragmatic map) or in the ethical discourse. Whereas the first option would not clearly separate arguments according to their thematic aspects, the second option conforms to the theory as it considers the nature of issues and examines them in corresponding discourses. However, one drawback of this method is that switching between discourses entails additional complexities and difficulties for managing and visualizing dependencies and thematic relations between them in real time conversations.

In sum, the illustrations show the different ways (with their pros and cons) to model the concepts for examination dialogs within the context of the Compendium. The resultant patterns can enrich Compendium's own catalogue of reusable conversation structures or issue-templates. Yet, the challenges of the two-level architecture mentioned call for the exploration of alternative ways to put theory into practice, as discussed next.

\section{DISCOURSIUM: A Tool and Methodology}

DISCOURSIUM can be conceived as both a tool and a methodology for facilitating structured deliberation on and critical examination of information objects (e.g., texts or a design proposal). The motivation for its development was to provide actors with a forum that instantiates the structures of the model and allows actors to participate directly in examination dialogs. However, some challenges related to the realization of the requirements from the theory forced us to make some compromise in the design.

As mentioned before, one of the rationales behind the two-level architecture (i.e., the clarification and the discourse level) is to separate conversations for clarifications and interpretations from argumentation around controversial claims. In addition, from the perspective of Habermas' 
(1984) discourse theory, an important criterion for good discourse is deliberativeness, which requires a dialogical form of discussion. On the other hand, from a practical point of view the full implementation of the concepts of two separate levels with dialogical discussion at each level may add additional complexity to the abstract concepts of the model. For example, allowing threaded discussions at each level may lead to inefficiency. In addition, as each discourse type is responsible for examining specific types of controversial issues, switching between discourses may in practice become challenging for the participants (Wellmer, 1999). Moreover, the management of the complex relationship between the discourses also requires additional cognitive

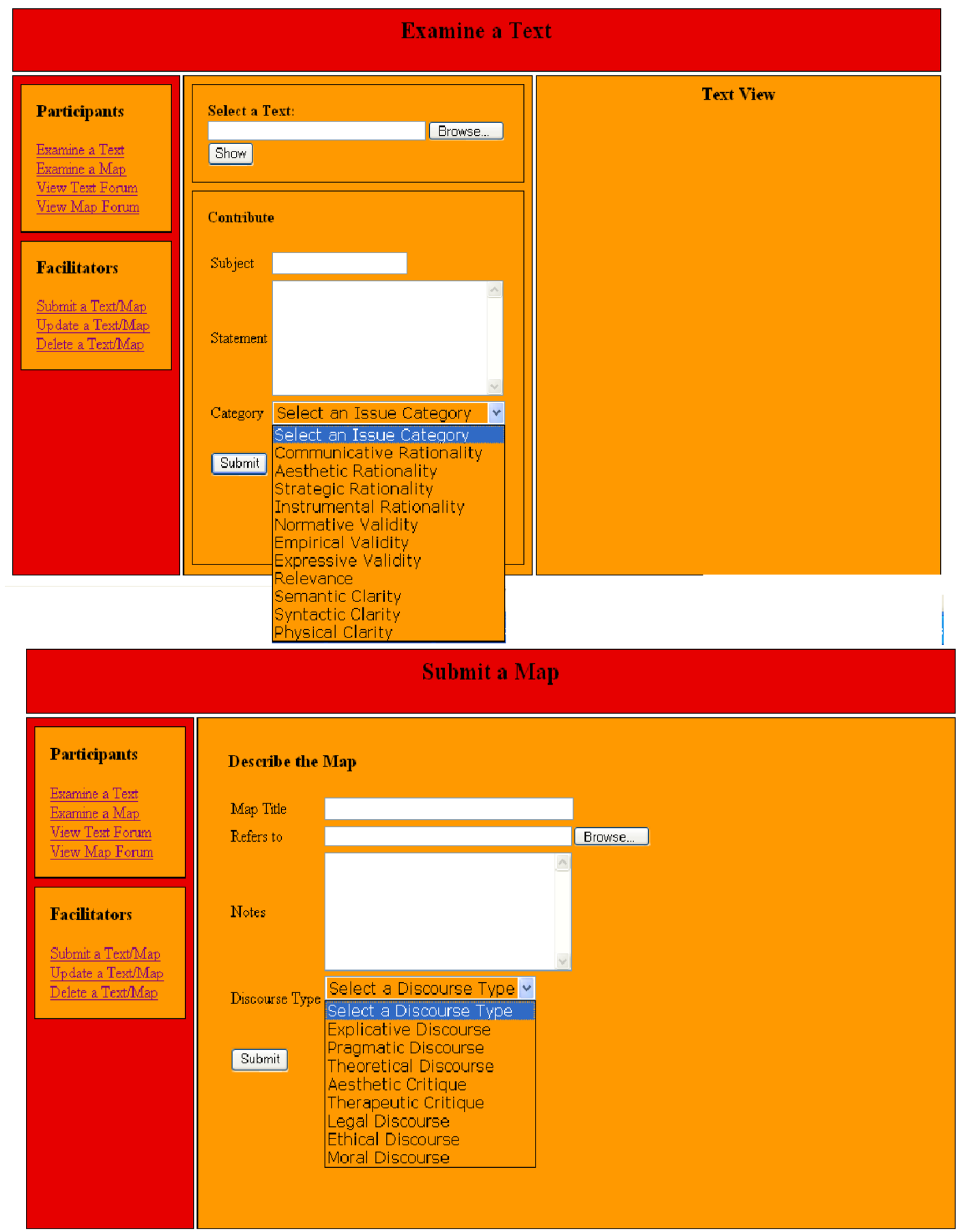

Figure 4: Screenshot for (a) examining texts and (b) submitting discourse maps. 
and technical efforts. Finally, usability challenges to the system may arise when it requires participants to possess communication knowledge, i.e., to know which discourses are for which types of controversies in order to place their positions/arguments in the appropriate discourses.

These challenges motivated us to explore a practical design solution. Without giving up the theoretical idea of separating discourses for argumentative examination of different issues, the following compromise solution has been implemented in DISCOURSIUM: only the clarification level from the model is implemented as a forum to enable participants to participate in critical examination dialogs. This forum is used for examining both information objects and argument maps. The main activities involve: (1) Users examine an information object; (2) A moderator creates argument maps for each discourse type; (3) Users examine the maps.

As shown in Figure 4(a), participants can upload a text or other information object to examine it critically. The system provides participants with categories of clarification issues, which they can select to make the semantics of their contributions explicit. In DISCOURSIUM, a facilitator is responsible for analyzing/summarizing contributions and identifying controversial positions for each issue. He or she also creates argument maps (or "discourse maps") for controversial issues and represents the controversial positions with associated pro or contra arguments. However, the current version of DICOURSIUM does not offer an editor for argument diagramming. Hence, facilitators have to use external tools and techniques for analysis and representation of arguments. They have to submit the discourse maps constructed into the system for further examination and specify each of them as shown in Figure 4(b). Then participants can upload discourse maps to examine them critically (Figure 5).

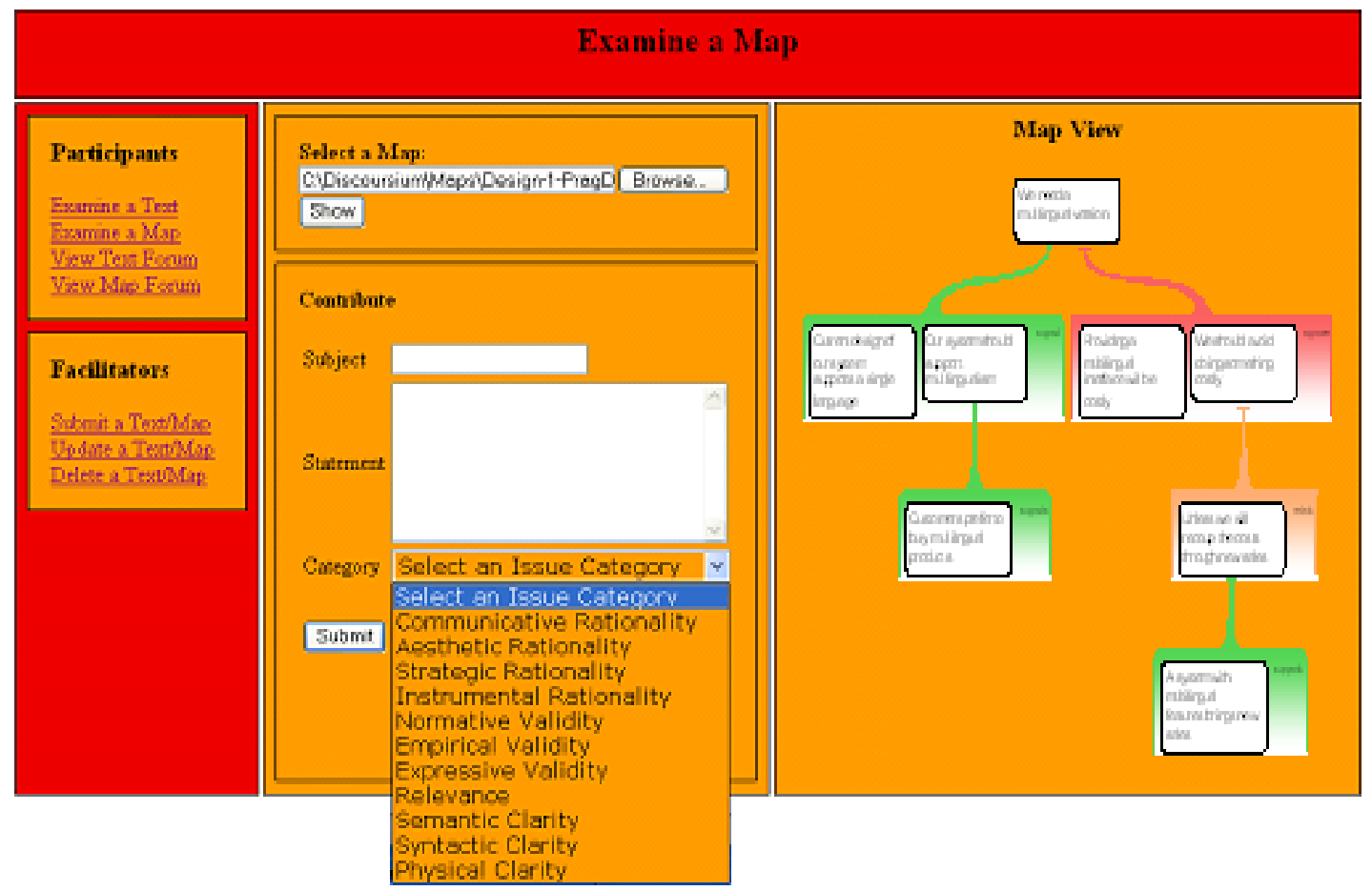

Figure 5: Screenshot for criticizing maps.

This design solution delegates much of the work to the facilitators and relieves participants of the burden of having to know which discourses are for which types of controversies in order to place their positions/arguments in the appropriate discourses. Participants only need to open each discourse map to see the controversial arguments and use the forum with the repertoire of critical issues to articulate their views/critiques on them. In other words, they indirectly interact with the 
discourse-level arguments of others and do not directly contribute to the positions in discourse maps. It is the task of the facilitators to analyze related contributions and to update the discourse maps for another round of discussions. The rationale for providing the same forum to examine both texts and discourse maps is to reduce the complexity of the theoretical model, as participants only need to learn how to use critical issues in examination dialogs.

Analyzing or constructing arguments is not an easy task, even for facilitators, and thus deserves some explicit attention at this point. A variety of tools and techniques have emerged from the theory of argumentation to support the task of analysis and representation/visualization of arguments (e.g., Kirschner, Buckingham Shum, \& Carr, 2003). One of them is Compendium with its IBIS method for diagramming as introduced above. The others are the Rationale system (van Gelder, 2007), which is used to construct the map in Figure 5, and the Araucaria system (Reed \& Rowe, 2004), which allows both the use of the conventional "box-and-arrow" approach and Toulmin-like schema representations. In his discourse theory, Habermas makes use of Toulmin's (1958) model of argumentation to explain the precise structure of cogent argumentation. Although the Toulmin schema is not regarded as the only way to represent the arguments in DISCOURSIUM, Toulmin-like structures (if desired) can be created through the use of many tools even though the means and constructs the tools provide are different.

For example, Compendium offers different terminology (i.e., Question node, Answer node, Pro node, and Con node), yet facilitators were able to rename the icons to represent argumentation in a given context. This flexibility of naming allows representing the multiple components of Toulmin's model of argument as well. A facilitator may introduce a controversial claim in the form of an issue (e.g., "Do we need X?") and link the available positions to them. Or, he or she can represent the controversial claim as a position statement (e.g., "We need X") and link the pro or counter-arguments to this position. Rebuttals (e.g., "Unless we can ...") and arguments supporting rebuttals can also be added.

Rationale offers two types of argument maps: Reasoning and Analysis. A reasoning map is used to show the relationship between claims or sentences that state a position, reason, or objection. An analysis map extends the reasoning map and facilitates understanding of multiple claims and their evaluation. The map in Figure 5 is constructed using the analysis map. The top node is the position, which is also called the contention, the conclusion, or the issue, depending upon the context. A reason is a claim which provides evidence that another claim is true. An objection is a claim which provides evidence that another claim is false. A rebuttal is an objection to an objection. In the argument map, the colors of the boxes signify the sort of claims they represent, e.g., green for supporting reasons, red for objections, and orange for rebuttals. Additionally, Rationale provides bases boxes, such as "expert opinion", "personal experience", "common belief", and "example", which can be used to display the basis of a claim. Finally, there are other labels to indicate the role of a reasoning box, such as "because" for a reason, "but" for an objection and "however" for a rebuttal.

Like Rationale, Araucaria employs a tree structure for mapping out the relationships between components in an argument. Once a diagram is constructed, Araucaria is able to transform this diagram into another, e.g., from the standard "box-and-arrow" into the Toulmin schema.

In conclusion, the different argument support systems provide different options and theoretical frameworks in which facilitators can work to analyze the discussions in DISCOURSIUM forum and to visualize them in a map. Having a Toulmin-like structure of an argument in mind, Yetim (2007) illustrated by means of simple examples that the same content can be visualized using these tools. As the tools provide different means or constructs to express and visualize arguments, facilitators need first of all to make a decision on which framework they want to work within. However, the selection of an argument mapping tool should not be based on its usability 
for a facilitator alone, but should rather consider whether its argument visualizations are also usable for the participants. The usability of the maps of different tools is a relevant issue worth further investigations. Assessing recent empirical research into the effectiveness of visualization tools, van den Braak, van Oostendorp, Prakken, and Vreeswijk (2006) conclude that most research indicates positive effects of the tools on the users' argumentation skills. After working with the three tools, we found that both Compendium and Rationale offer advanced visualization options, whereas Aracuaria's strength is its ability to provide an interlingua for different frameworks and to translate between diagrams.

Whatever tool is used for mapping, it is particularly important to consider that a discourse map has a main controversial issue or validity claim to which arguments in the map provide supporting or challenging reasons. As mentioned above, arguments in a discourse map (e.g., in the pragmatic discourse) can have different types of reasons (e.g., ethical or aesthetic reasons). However, when the validity of these reasons is challenged an extensive discussion should not be carried out in the same map. Instead, facilitators can create related submaps for each of them (e.g., ethical and aesthetical discourse maps) and link them to the corresponding position. This conforms to the theoretical idea of using different types of discourses for different validity claims. In addition, it has practical value because a submap that captures the justification of a specific claim can be linked to other discourse maps where the corresponding claim is used for supporting or challenging arguments. On the other hand, this requires effective management and presentation of interlinked maps in order to make them usable.

Finally, it should be mentioned that visualized arguments for each discourse can be critically examined or evaluated in different ways. The current version of DISCOURSIUM allows participants to freely verbalize their critiques and categorize them. However, it does not provide any guidance in terms of concrete questions that might be relevant to ask in specific situations or to criticize specific positions. The next section elaborates on this issue.

\section{Criticizing Arguments in Discourse Maps}

This section aims to take the realization of the critical concepts within the context of Compendium and DISCOURSIUM one step further. It explores the issue of whether, and how, the categories of issues can be instantiated with concrete and context-specific questions in order to provide dialog participants with questions for particular types of information (e.g., for criticizing opinions or examples). For this purpose, we first introduce an approach from argumentation theory to critically examining arguments and illustrate it with an example from the literature. With the help of the same example, we discuss how our question categories can alternatively be used for the same purpose to encourage practitioners to design critical issues for other cases.

To articulate our position clearly, let us first illustrate by means of an example map how different sources can be used to justify claims in an argument map. Figure 6 shows an example map adopted from the Rationale system (www.austhink.org). The relevant issue here is how the content of this map or the assumptions behind the statements can be criticized. The approach advocated in DISCOURSIUM is to ask some critical questions in a forum-like discussion. Another approach suggests using argumentation schemes from argumentation theory (Walton, 1996), such as argument from expert opinion, argument from example, and applying the critical questions associated with each scheme to evaluate arguments. In other words, when someone refers to expert opinion (as shown in the map) and argues that s/he should be believed because an expert agrees with her/him, a schema can help to identify what the assumptions behind such an argument are and how such an argument can be challenged.

Argumentation schemes represent stereotypical kinds of ordinary reasoning and are used to identify, analyze, and evaluate arguments. Walton (1996) suggested a set of common schemes, in- 


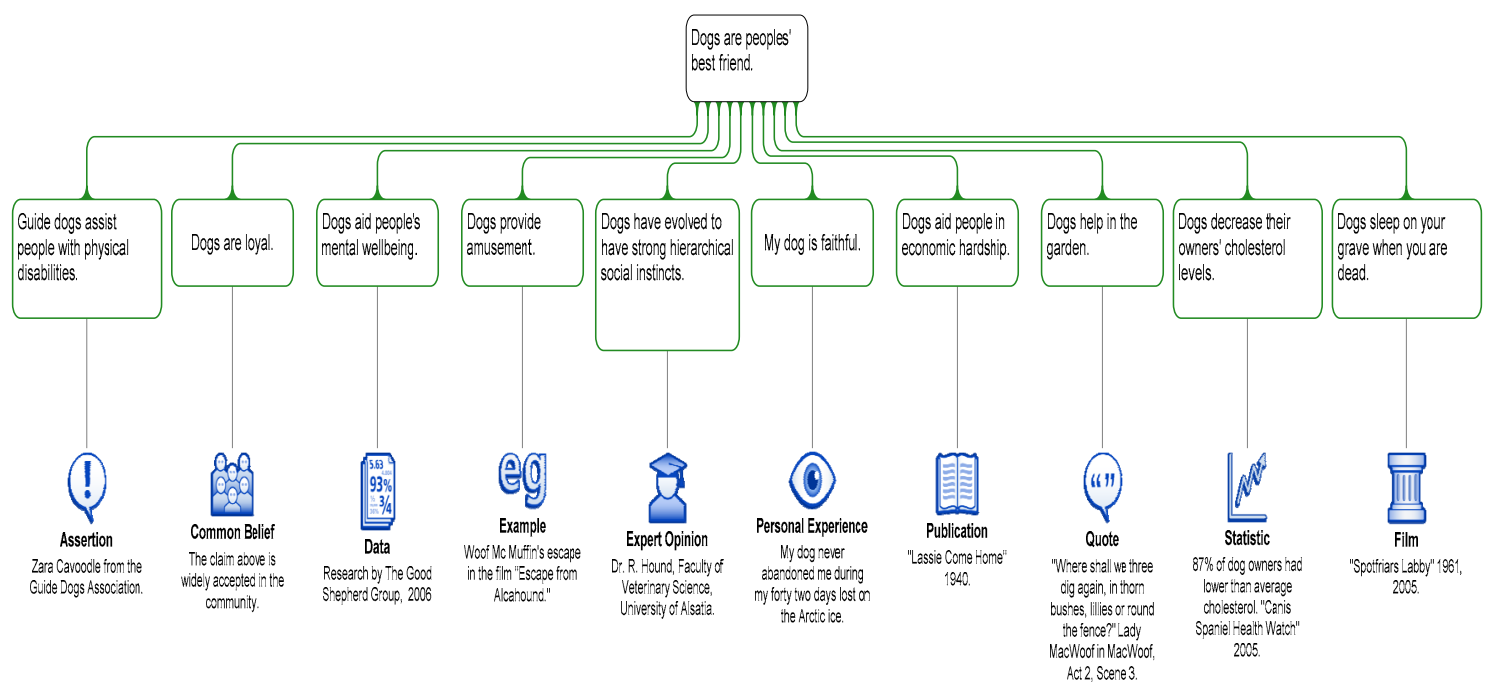

Figure 6: Examples of arguments in a map (adopted from Rationale, (C) Austhink Software).

cluding argument from expert opinion, argument from example, argument from sign, argument from analogy, argument from popular opinion, argument from an established rule, and argument from consequence. These schemes can fail, for example when challenged by critical questions. Each scheme has a special set of critical questions that pinpoint the assumptions behind an argument. An argument is evaluated using the critical questions.

As a case example, consider the scheme for "argument from expert opinion". Walton regards it as fundamental to examination dialogs and presents it in the following way (Walton, 2006, p.750):

\section{Appeal to expert opinion}

Source Premise: Source E is an expert in subject domain S containing proposition A.

Assertion Premise: E asserts that proposition A (in domain S) is true (false).

Warrant Premise: If source $\mathrm{E}$ is an expert in subject domain $\mathrm{S}$ containing proposition $\mathrm{A}$, and $\mathrm{E}$ asserts that proposition $\mathrm{A}$ (in domain $\mathrm{S}$ ) is true (false), then A may plausibly be taken to be true (false).

Conclusion: A may plausibly be taken to be true (false).

For the argument to be of this type, it must have the three types of premises represented in the argumentation scheme. According to Walton (2006), there are six critical questions matching this scheme.

1. Expertise Question: How credible is E as an expert source?

2. Field Question: Is E an expert in the field that A is in?

3. Opinion Question: What did E assert that implies A?

4. Trustworthiness Question: Is E personally reliable as a source?

5. Consistency Question: Is A consistent with what other experts assert?

6. Backup Evidence Question: Is E's assertion based on evidence?

The critical questions represent different ways of challenging the premises of appealing to expert opinion. The idea is that this argument scheme with its associated questions can be used to evalu- 
ate any given case in which appeal to expert opinion has been used as an argument. Similarly, critical questions associated with other schemes can be used for other types of arguments.

This brief introduction with a case example suffices to articulate and justify our position. First of all it should be noted that there is no doubt concerning the usefulness of argumentation schemes for analyzing and evaluating arguments, at least from a theoretical point of view. However, in practice they may appear too complex to users, except experts; thus, they raise practical issues such as: How many schemes can easily be learned by the users? How much from this rich set of schemes should be provided as templates without making the system too complex for the user? Can users easily identify in a dialog which scheme applies, in order to be able to ask the matching critical questions? Perhaps more importantly, do users need to know the schemes to ask critical questions?

Our review of the critical questions matching many schemes in Walton (1996) indicates that many critical questions - if not all - can be reinterpreted or regarded as instances or sub-issues of our issue categories. Table 1 illustrates how many of the critical questions from the above example and, also, some additional questions can be assigned to our categories to provide users with a set of concrete questions for challenging arguments from expert opinion. Similarly, critical questions matching other schemes can be analyzed and integrated in the categories.

Table 1: : Critical Questions for Examining Expert Opinion

\begin{tabular}{|c|c|}
\hline Categories of Issues & Examples \\
\hline Physical Clarity & "Is the expression of the expert perceivable/readable by all?" \\
\hline Syntactic Clarity & "Is the expression of the expert syntactically clear?" \\
\hline Semantic Clarity & "Is the meaning of what expert said comprehensible?" \\
\hline Relevance & "Is the assertion of the expert relevant to the domain?" \\
\hline Expressive Validity & "Is the expert known to be trustworthy?" \\
\hline Empirical Validity & "Is expert's assertion based on evidence?" \\
\hline Normative Validity & "Is the expert really authoritative in the relevant field?" \\
\hline Instrumental Rationality & $\begin{array}{l}\text { "Is the expert's advice (when followed) an efficient way of } \\
\text { acting in the current context?" }\end{array}$ \\
\hline Strategic Rationality & $\begin{array}{l}\text { "Is the assertion covertly motivated by expert's egocentric } \\
\text { calculation of success?" }\end{array}$ \\
\hline Aesthetic Rationality & $\begin{array}{l}\text { "Is the expression of the expert emotionally loaded/ aestheti- } \\
\text { cally appealing?" }\end{array}$ \\
\hline
\end{tabular}

In addition, the maps constructed by the facilitators can also be critically examined. Table 2 illustrates some example questions. In this case, the respondent(s) to the critical questions is/are the facilitators(s) who analyzed the discussions and designed the maps. Thus, facilitators should be seen in a collaborative examination dialog with other participants.

All in all, this section has started from the premise that providing participants with a set of context-sensitive issues along the issue categories may be of value for critical examination of the contents and forms of the argument maps. It has illustrated with examples how the abstract cate- 
gories of issues presented in this paper can provide orientation for the creation of semantically related sub-issues for specific cases. This section thus argues that the categories can also be used to categorize many other concrete critical questions to support participants to articulate their critiques with respect to both the content of a map (i.e., arguments of participants) and the design of a map (for which the facilitator is responsible).

Table 2: Critical Questions for Examining the Design of Argument Maps

\begin{tabular}{|l|l|}
\hline \multicolumn{1}{|c|}{ Categories of Issues } & \multicolumn{1}{c|}{ Examples } \\
\hline Physical Clarity & "Are texts/nodes/links on the map readable/visible?" \\
\hline Syntactic Clarity & "Are expressions/links on the map syntactically correct?" \\
\hline Semantic Clarity & "Are texts/links on the map comprehensible?" \\
\hline Relevance & "Are all relevant arguments included in the map?" \\
\hline Expressive Validity & $\begin{array}{l}\text { "Do expressions on the map reflect the sincere intentions of } \\
\text { their owners?" }\end{array}$ \\
\hline Empirical Validity & "Are all claims on the map really asserted?" \\
\hline Normative Validity & $\begin{array}{l}\text { "Do representations on the map violate any legal norm or } \\
\text { cultural value (e.g., ownership, copyrights)?" } \\
\text { "Are boxes/nodes on the map efficiently organized?" }\end{array}$ \\
\hline Instrumental Rationality & $\begin{array}{l}\text { "Are some arguments strategically omitted/ misinterpreted/ } \\
\text { wrongly placed?" } \\
\text { Strategic Rationality }\end{array}$ \\
\hline Aesthetic Rationality & "Do symbols/colors on the map look beautiful?" \\
\hline
\end{tabular}

\section{Discussion and Conclusions}

This paper argued that the examination of information needs to be conducted in a discursive and structured manner. This is based on the premise that - in the light of the uncertainties with respect to the comprehensibility, relevance, validity, and rationality of information - the right thing to do is to keep an open mind and remain open to discourse and critics with new arguments. For this purpose, it briefly described the structural characteristics of examination dialogs and presented the arrangement of some basic issues and discursive concepts for examining information in a systematic way. In addition, some reflections on the pros and cons of two realization options of these theoretical ideas have been presented. These include their modeling as templates within Compendium for supporting critical team deliberation as well as their realization as features of a prototype system DISCOURSIUM for facilitating examination dialogs in a structured forum. Finally, the issue categories have been further investigated with respect to their applicability to categorize concrete critical questions in order to provide participants with means for critically examining argument maps (i.e., their contents and design) without the need to possess knowledge of the argument schemes. All in all, this paper claims to make a contribution by presenting a discursive approach to examine information within the framework of communicative action and providing some reflections on their realization options. 
This paper raises several issues that may be of value to researchers and practitioners. As the implemented artifacts have not yet been evaluated in real situations, researchers may further investigate the complexities of live discourses in the context of the proposed modeling approach.

Practitioners may use the categories to design other context-sensitive sets of issues. This can be done either along the argument schemas as illustrated with the case example or along the semantic of the issue categories, i.e., collecting concrete issues related to normative validity (e.g., legal, ethical, or moral issues) or aesthetical rationality, and so on. Further useful questions can be found, for example, by studying different information quality dimensions (e.g., Knight \& Burn, 2005; Gackowski, 2006) and investigating whether, and to what extent, they can be integrated into the categories of issues. Such a set of context-sensitive questions can be useful both in the context of Compendium and DISCOURSIUM. However, some aspects of the current version of the DISCOURSIUM need to be redesigned to enable participants to select elements of argument maps (e.g., expert opinion) and to view the set of related questions.

Further future issues concern the investigation of the usability of the artifacts developed, particularly in different cultural contexts (Kovacic, 2001, Smith \& Yetim, 2004). These include the usability of the question categories and argument maps for the participants as well as that of argument visualization tools for facilitators.

\section{Acknowledgements}

I would like to thank Zlatko Kovacic (Associate Editor) and anonymous reviewers for their valuable comments on the first draft of this paper.

\section{References}

Alavi, M., \& Leidner, D. E. (2001). Review: Knowledge management and knowledge management systems: Conceptual foundations and research issues. MIS Quarterly, 25(1), 107-136.

Berger, P., \& Luckmann, T. (1966). The social construction of reality. Harmondsworth: Penguin Books.

Boisot, M. H. (1995). Information space: A framework for learning in organizations, institutions and culture. London: Routledge.

Buckingham Shum, S. (2006). Sensemaking on the pragmatic web: A hypermedia discourse perspective. Proceedings of 1st International Conference on the Pragmatic Web. Stuttgart, Germany.

Capurro, R. (2000). Ethical challenges of the information society in the $21^{\text {st }}$ century. International Information \& Library Review, 32, 257-276.

Cohen, E. (1999). Reconceptualizing information systems as a field of the transdiscipline informing science: From ugly duckling to swan. Journal of Computing and Information Technology, 7(3), 213-219.

Conklin, J. (2005). Dialogue mapping: Building shared understanding of wicked problems. Chichester: Wiley.

Dretske, F. (1981). Knowledge and the flow of information. Cambridge, MA: MIT Press.

Drucker, P. F. (1994). Post-capitalist society. New York: Harper Business.

Dunne, P. E., Doutre, S., \& Bench-Capon, T. (2005). Discovering inconsistency through examination dialogues. Proceedings of International Joint Conference on Artificial Intelligence (IJCAI-05), Edinburgh, pp. 1560-1561.

Farnham, S., Chesley, H. R., McGhee, D. E., Kawal, R., \& Landau, J. (2000). Structured online interactions: Improving the decision-making of small discussion groups. Proceedings of the ACM Conference on Computer-Supported Cooperative Work (CSCW'00), ACM Press, New York, NY, USA. 
Gackowski, Z. J. (2006). Diagnostic and functional dependencies of credibility. Informing Science: the International Journal of an Emerging Transdiscipline, 9, 225-241. Retrieved from http://inform.nu/Articles/Vol9/v9p225-241Gackowski97.pdf

Gill, G., \& Bhattacherjee, A. (2007). The informing sciences at a crossroads: The role of the client. Informing Science: the International Journal of an Emerging Transdiscipline, 10, 17-39. Retrieved from http://inform.nu/Articles/Vol10/ISJv10p017-039Gill317.pdf

Greisdorf, H. (2000). Relevance: An interdisciplinary and information science perspective. Informing Science: the International Journal of an Emerging Transdiscipline, 3(2), 67-72. Retrieved from http://inform.nu/Articles/Vol3/v3n2p67-72.pdf

Habermas, J. (1984). The theory of communicative action: Reason and the rationalization of society (Vol. 1). Boston, MA: Beacon Press.

Habermas, J. (1996). Between facts and norms. Boston, MA: MIT Press.

Hoppenbrouwers, S., \& Weigand, H. (2000). Meta-communication in the language action perspective. In: M. Schoop \& C. Quix, (eds.), Proceedings of the Fifth International Workshop on the LanguageAction Perspective on Communication Modelling.

Karamüftüoglu, M. (1998). Collaborative information retrieval: Towards a social informatics view of IR interaction. JASIS, 12, 1070-1080.

Kirschner, P. A., Buckingham Shum, S., \& Carr, C. S. (2003). Visualizing argumentation: Software tools for collaborative and educational sense-making. London: Springer Verlag.

Klamma, R., Spaniol, M., \& Jarke, M. (2005). MECCA: Hypermedia capturing of collaborative scientific discourses about movies. Informing Science: the International Journal of an Emerging Transdiscipline, 8, 3-38. Retrieved from http://inform.nu/Articles/Vol8/v8p003-038Klamma.pdf

Knight, S.-A. \& Burn, J. (2005). Developing a framework for assessing information quality on the world wide web. Informing Science: the International Journal of an Emerging Transdiscipline, 8, 159-172. Retrieved from http://inform.nu/Articles/Vol8/v8p159-172Knig.pdf

Kovacic, Z. (2001). Communicating culture: An exploratory study of the key concepts in Maori culture on Maori web sites. Informing Science: the International Journal of an Emerging Transdiscipline, 4(2), 53-59. Retrieved from http://inform.nu/Articles/Vol4/v4n2p053-059.pdf

Kuhlen, R. (1999). Die konsequenzen von informationsassistenten. Was bedeutet informationelle autonomie oder wie kann vertrauen in elektronische dienste in offenen informationsmärkten gesichert werden? [The consequences of information assistants. What does informational autonomy mean or how can trust in digital services be ensured in open information markets?] Frankfurt: Suhrkamp.

Kunz, W., \& Rittel, H. W. J. (1970). Issues as elements of information systems. Institute of Urban and Regional Development. Working Paper 131. University of California, Berkeley.

Machlup, F. (1980). Knowledge: Its creation, distribution, and economic significance (Vol. I). Princeton, NJ: Princeton University Press.

Nonaka, I., \& Takeuchi, H. (1995). The knowledge-creating company. How Japanese companies create the dynamics of innovation. Oxford: Oxford University Press.

Norman, D. A. (2004). Emotional design. Why we love (or hate) everyday things. Cambridge, MA: Basic Books.

Ravenscroft, A., \& McAlister, S. (2006). Digital games and learning in cyberspace: A dialogical approach. E-Learning Journal, 3(1), 37-50.

Reed, C., \& Rowe, G. (2004). Araucaria: Software for argument analysis, diagramming and representation. International Journal of AI Tools, 14, 3-4.

Schön, D. (1983). The reflective practitioner: How professionals think in action. New York: Basic Books.

Schutz, A. (1970). Reflections on the problem of relevance. New Haven: Yale University Press. 
Seel, M. (1985). Die kunst der entzweiung: Zum begriff der ästhetischen rationalität. [The art of divisiveness: On the notion of aesthetic rationality] Frankfurt am Main: Suhrkamp.

Smith, A. \& Yetim, F. (2004). Global human-computer systems - Cultural determinants of usability. [Special issue]. Interacting with Computers, 1 .

Stahl, B. C. (2006). On the difference or equality of information, misinformation, and disinformation: A critical research perspective. Informing Science: the International Journal of an Emerging Transdiscipline, 9, 83-96. Retrieved from http://inform.nu/Articles/Vol9/v9p083-096Stahl65.pdf

Spender, J.-C. (1996). Making knowledge the basis of a dynamic theory of the firm. Strategic Management Journal, 17, 54-62

Te'eni, D. (2001). Review: A cognitive-affective model of organizational communication for designing IT. MIS Quarterly, 25(2), 251-312.

Toulmin, S. (1958). The uses of argument. Cambridge: Cambridge University Press.

Tractinsky, N., Katz, A. S., \& Ikar, D. (2000). What is beautiful is usable. Interacting with Computers, 13, 127-145.

Tuomi, I. (1999). Data is more than knowledge: Implications of the reversed hierarchy for knowledge management and organizational memory. Proceedings of the Thirty-Second Hawaii International Conferences on Systems Sciences, IEEE Computer Society Press, Los Alamitos, CA.

Ulrich, W. (2001). Philosophical staircase for information systems definition, design and development. Journal of Information Technology Theory and Application, 3, 55-84.

Uren, V., Buckingham Shum, S., Bachler, M., \& Li, G. (2006). Sensemaking tools for understanding research literatures: Design, implementation and user evaluation. International Journal of Human Computer Studies, 64, 420-445.

van den Braak, S.W., van Oostendorp, H., Prakken, H., \& Vreeswijk, G. A. (2006). A critical review of argument visualization tools: Do users become better reasoners? Proceedings of the ECAI-06 Workshop.

van Gelder, T. (2007). The rationale for rationale ${ }^{\mathrm{TM}}$. Department of Philosophy, University of Melbourne and Austhink Software Pty Ltd.

Walton, D. (1996). Argumentation schemes for presumptive reasoning. Mahwah, N.J.: Erlbaum.

Walton, D. (2006). Examination dialogue: An argumentation framework for critically questioning an expert opinion. Journal of Pragmatics, 38, 745-777.

Walton, D. (2007). The speech act of clarification in a dialogue model. Studies in Communication Sciences, 7, 127-159.

Walton, D., \& Krabbe, E. C. (1995). Basic concepts of interpersonal reasoning. State University of New York Press.

Wellmer, A. (1999). Ethik und dialog: Elemente des moralischen urteils bei Kant und in der diskursethik. [Ethics and dialog: Elements of moral judgment in Kant and discourse ethics] Frankfurt: Suhrkamp.

Yetim, F. (2004). Universal actability: Towards an integral understanding of universal usability, (intercultural) action competence, and information systems actability. Proceedings of the Language-Action Perspective on Communication Modeling (LAP 2004), June 2-3, Rutgers University, NJ, USA.

Yetim, F. (2006). Acting with genres: Discursive-ethical concepts for reflecting on and legitimating genres. European Journal of Information Systems, 15(1), 54-69.

Yetim, F. (2007). DISCOURSIUM for cooperative examination of information in the context of the pragmatic web. Proceedings of the $2^{\text {nd }}$ International Pragmatic Web Conference, 22-23 October, Tilburg, Holland.

Zack, M. H. (1999). Managing codified knowledge. Sloan Management Review, 40(4), 45-57. 


\section{Biography}

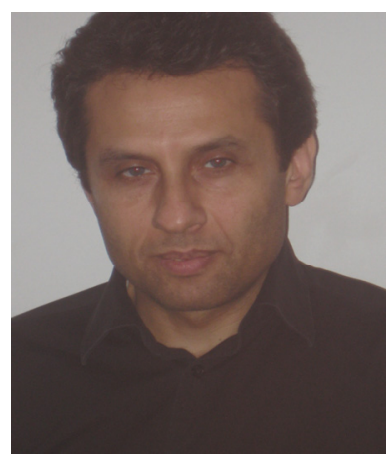

Fahri Yetim received his B.S. in Computer Science (1986), M.S. in Information Science (1989), and Ph.D. in Information Science (1994) in Konstanz, Germany. He held a DAAD Professorship (Langzeitdozentur) at the Marmara University Istanbul, German Department of Information Systems (1997-2000), was Visiting Professor at the New Jersey Institute of Technology, USA (2001-2004), and Deputy Professor (Vertretungsprofessor) at the Cologne University of Applied Sciences $(2006$ - 2007). Currently, he is a Senior Researcher at the University of Siegen. 